\title{
PERENCANAAN VIRTUALISASI LAYANAN PENGADAAN SECARA ELEKTRONIK PEMERINTAH KABUPATEN BADUNG MENGGUNAKAN METODE BLUE OCEAN STRATEGY DAN BALANCED SCORECARD
}

\author{
I Made Aryawan ${ }^{1}$ Linawati $^{2}$, I.A Dwi Giriantari ${ }^{3}$
}

\begin{abstract}
The main obstacles holding LPSE in Indonesia today is the limited available resources (infrastructure and competent human resources) so it needs proper governance to maintain the availability of service in order to increase the procurement credibility of government goods or services. Virtualization Technology Utilization proposed as an alternative solution considering the efficiency, effectiveness and ease of maintenance, is considered able to accelerate the realization of a reliable and accountable LPSE so it can increase the participation of service users. This research discussed the Planning of Virtualization based on Blue Ocean Strategy analyses (BOS) and Balanced Scorecard (BSC), where the virtualization creates innovations value for LPSE Badung and becomes a real step towards BOS considering it has not been widely adopted by other LPSE. BOS gives a picture of the current organization and desired ideal condition, while the optimization and management of variable accuracy achieved through the implementation of Key Performance Indicators / KPI from various perspectives within the framework of the BSC.

Canvas mapping strategy in this research, produce four steps framework namely: (1) the elimination step is to negate Internet access failure, (2) the step to reduce application error, access difficulties, the difficulties in operating the applications and connection interference, (3) the step to increase the availability of information, the speed and the smoothness of the transaction process, ease of complains, the quality of support services, data security system and (4)the step to create service interference resistance.

The virtualization implementation also gives a positive value towards the performance of LPSE services in terms of user satisfaction level, where in general the achievement recorded close to the value of user expectation, even in the services related to the handling of complaints, the performance achievement showed the value that exceeds user expectation. Further optimization and virtualization planning accuracy, conducted through the establishment of 11 Key Performance Indicators / KPI in 6 perspectives is the development of the four main perspectives BSC framework.
\end{abstract}

Keywords - Virtualization, Blue Ocean Strategy, Balanced Scorecard, LPSE, e-proc.

\footnotetext{
${ }^{1}$ Mahasiswa, PNS Pemkab Badung, Jl. Raya Sempidi Mangupura, Badung - Bali (tlp: 0361-422870; email:arya_one@yahoo.com )

${ }^{2,3}$ Dosen,Magister Teknik Elektro PPs Universitas Udayana, Jl.PB Sudirman Denpasar-Bali, (telp/fax. 0361-239599; e-mail: linawati@unud.ac.id, ${ }^{3}$ dayu.giriantari@yahoo.com
}

Intisari- Kendala utama penyelenggaraan LPSE di Indonesia saat ini adalah keterbatasan sumber daya yang dimiliki (infrastruktur, SDM yang kompeten) sehingga dibutuhkan tata kelola yang tepat untuk menjaga availabilitas dan reliabilitas layanan guna meningkatkan kredibilitas pengadaan barang/jasa pemerintah. Pemanfaatan Teknologi Virtualisasi diusulkan menjadi solusi alternatif mengingat efisiensi, efektifitas serta kemudahan maintenance-nya, ditengarai mampu mempercepat terwujudnya LPSE yang handal dan akuntabel sehingga dapat meningkatkan partisipatori pengguna layanan. Dalam penelitian ini dibahas Perencanaan Virtualisasi menggunakan metode Blue Ocean Strategy (BOS) dan Balanced Scorecard (BSC), dimana virtualisasi menciptakan inovasi nilai bagi LPSE Badung dan menjadi langkah nyata menuju $B O S$, mengingat hal ini belum banyak diterapkan oleh LPSE lain. BOS memberikan gambaran kondisi organisasi saat ini serta kondisi ideal yang diinginkan, sementara optimalisasi dan akurasi pengelolaan variabel dicapai melalui penetapan Key Performance Indicator/KPI dari berbagai perspektif dalam kerangka kerja $B S C$.

Pemetaan canvas strategy dalam penelitian ini, menghasilkan kerangka kerja 4 langkah: (1) langkah eliminasi, yaitu meniadakan kegagalan akses, (2) langkah mengurangi: kesalahan aplikasi, kesulitan akses, kesulitan mengoperasikan aplikasi, dan gangguan koneksi, (3) langkah meningkatkan: ketersediaan informasi, kecepatan dan kelancaran transaksi, kemudahan penyampaian keluhan, kualitas layanan bantuan, sistem kemanan data, serta (4) langkah menciptakan: ketahanan layanan terhadap gangguan. Implementasi virtualisasi juga memberikan nilai positif pada persepsi tingkat kepuasan pengguna, dimana secara umum capaian kinerja tercatat mendekati nilai ekspektasi pengguna, bahkan capaian kinerja terkait penanganan keluhan menunjukkan nilai melebihi ekspektasi pengguna. Selanjutnya optimalisasi dan peningkatan akurasi perencanaan virtualisasi, dilakukan melalui penetapan 11 Key Performance Indicators/KPI dalam 6 perspektif yang merupakan pengembangan terhadap 4 perspektif utama kerangka kerja $B S C$.

Kata kunci- Virtualisasi, Blue Ocean Strategy, Balanced Scorecard, LPSE, e-proc.

\section{Pendahuluan}

Disadari atau tidak perkembangan TIK yang begitu cepat beberapa tahun belakangan ini telah berdampak luas pada semua sendi kehidupan termasuk dibidang pemerintahan utamanya pada pelayanan publik seperti pelaksanaan pengadaan barang/jasa. Terwujudnya layanan yang lebih efektif, efisien, transparan dan akuntabel atau Pelayanan Prima adalah bentuk signifikan dampak paradigma yang berubah 
tersebut, yang menuntut para penyedia layanan memperhatikan dua isu penting yaitu availabilitas dan reliabilitas layanan. Disisi lain, implementasi LPSE seringkali terkendala terutama oleh terbatasnya sumber daya, seperti infrastruktur, biaya serta personil yang kompeten. Fenomena ini tentu berpengaruh pada kinerja LPSE dalam memfasilitasi penggunanya (ULP/Penyedia) agar layanan e-proc yang menjadi tanggung jawabnya dapat terlaksana dengan baik dan berkelanjutan. Dengan kata lain, LPSE harus bisa menjaga ketersediaan maupun kehandalan layanannya seperti yang diamanatkan oleh Pasal 9 Peraturan Kepala (Perka) Lembaga Kebijakan Pengadaan Barang/Jasa Pemerintah (LKPP) Nomor 2 Tahun 2010 tentang Layanan Pengadaan Secara Elektronik [1].

Ketimpangan kondisi ini tentu perlu dicarikan solusi dan alternatif yang dapat ditempuh adalah penggunaan Teknologi Virtualisasi pada pengelolaan server yang dimiliki. Beberapa hasil penelitian sebelumnya menunjukkan bahwa Teknologi Virtualisasi terindikasi bisa memberi efisiensi dan secara signifikan cukup efektif mempengaruhi performa dan kinerja server. Virtualisasi menjanjikan penyelesaian yang lebih efektif dalam manajemen sumber daya dalam peningkatan manfaat / utilitas, efisiensi finansial serta kemudahan maintenance [2] [3], yang merupakan beberapa hal penting untuk menunjang peningkatan kinerja layanan yang pada akhirnya dapat mempercepat terwujudnya LPSE yang handal, efektif, efisien, transparan dan akuntabel.

\section{TeKNOLOGI VIRTUALISASI}

\section{A. Konsep Virtualisasi}

Dalam teknologi virtualisasi, beberapa sistem operasi yang berbeda dimungkinkan dapat bekerja sekaligus secara bersamaan dengan hanya menggunakan satu perangkat komputer saja [4] [5] [6] [7], sehingga menjadikannya sebagai sebuah konsep dengan kemampuan menciptakan beberapa lingkungan berbeda pada saat yang sama dalam sebuah komputer dan lingkungan itu dikenal sebagai Virtual Machine (VM) yang kemudian menggantikan konsep "Satu server satu aplikasi" [8], seperti Gambar 1 yang menyajikan ilustrasi arsitektur sistem virtualisasi secara umum [4].

Virtualisasi bisa disebut sebagai langkah mengoptimalkan pendayagunaan aset TIK, dimana pengurangan biaya dan penyederhanaan pengelolaan diperoleh melalui pemanfaatan konsep cluster high availability pada virtualisasi server [9]. Kondisi ini dapat berlangsung, melalui eksistensi processor ganda sehingga dimungkinkan untuk menjalankan berbagai aplikasi berbeda secara bersamaan [3] yang akhirnya bermuara pada optimalisasi penggunaan sumber daya, dimana biasanya terpakai sekitar 10 - 15\% saja [9].

Rusydi Umar [4] mengemukakan bahwa Virtualisasi adalah teknologi yang memungkinkan sebuah komputer fisik berlaku seakan-akan sebagai dua buah atau lebih komputer nonfisik/komputer virtual [10], sementara Omkar Kulkarni, dkk [2] menyampaikan bahwa virtualisasi merupakan usaha optimalisasi pemanfaatan beragam resources TI yang tersedia, dimana lingkungan kerja yang berbeda dapat dibuat dengan kombinasi atau pembagian resources sebuah server menggunakan cara tertentu antara lain simulasi, agregasi/partisi, emulasi serta time sharing [11], sedangkan virtualisasi menurut Rio Rasian dan Petrus Mursanto [9] merupakan metode yang digunakan untuk menutupi sifat fisik suatu resource komputer atau suatu cara agar menghasilkan hal tertentu secara non-fisik, suatu yang tidak nyata.

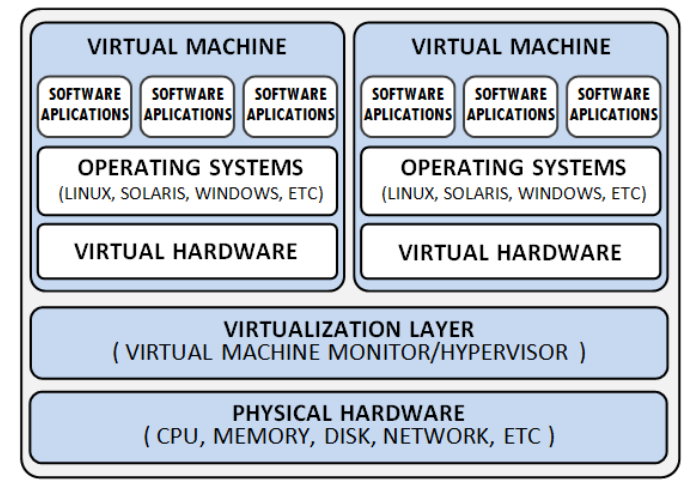

Gambar 1. Arsitektur Sistem Virtualisasi [4]

\section{B. Klasifikasi Virtualisasi}

Berbagai sebutan virtualisasi diberikan berdasarkan perbedaan tekniknya, antara lain Full/Native Virtualization, Para Virtualization, Emulation, OS Level Virtualization, serta Resource Virtualization [2], sementara istilah Virtualisasi Level Hardware, Virtualisasi Level Sistem Operasi dan Virtualisasi Level Aplikasi adalah penggolongan menurut penempatan layernya [12].

Full/Native Virtualization memanfaatkan sebuah hypervisor untuk mengkoneksikan guest dan hardware, dimana perangkat non-fisik ini mengabstraksi hardware, serta mengijinkan sebuah OS tak termodifikasi dapat beroperasi melalui instruksinya kepada hardware.

Para Virtualization memiliki kemiripan dengan Full/Native Virtualization, namun terdapat modifikasi OS pada guest serta di butuhkan trapping (kompilasi ulang), sementara dalam Emulation, hardware akan melaksanakan suatu mode dan menghasilkan hardware secara non-fisik guna meniru hardware yang dikehendaki.

\section{Piranti Lunak Virtualisasi}

Berbagai piranti lunak/software virtualisasi saat ini banyak beredar di pasaran dengan bermacam keunggulan serta kelemahannya, diantaranya : Microsoft Hyper-V, LinuxVserver, OpenVZ, Sun xVM VirtualBox, Microsoft VirtualServer, VMware ESX/ESXi, VMware Server, dan Xen [9].

Salah satu software virtualisasi keluaran Microsoft yang mendukung sistem operasi desktop/server dan beberapa distribusi GNU/Linux adalah Microsoft Hyper-V, sedangkan Linux-Vserver serta OpenVZ adalah software virtualiasi yang didistribusikan sebagai freeware (software bebas) dengan kemampuan OS-level virtualization pada kernel Linux, sementara Sun xVM VirtualBox adalah software keluaran Sun Microsystem bertipe hosted dengan fitur tambahan berupa 
Remote Desktop Protocol, USB, iSCSI, dan lain- lain yang telah tersedia pada versi proprietarynya.

Satu-satunya software virtualisasi server sebelum Hyper-V bertipe hosted serta mendukung native atau hardware-assisted virtualization adalah Microsoft Virtual Server yang kini telah menjadi freeware. VMware ESX/ESXi adalah piranti lunak bertipe bare-metal dari VMware dan VMware Server NMware GSX Server adalah software unggulan VMware, sedangkan Xen adalah software tipikal bare-metal yang sekarang dikembangkan oleh komunitas sebagai freeware dan melibatkan beberapa vendor teknologi informasi ternama, diantaranya Citrix, IBM, Intel, HP, Novell, Red Hat, Sun Microsystems, serta Oracle

\section{Manfaat Virtualisasi}

Implemantasi virtualisasi oleh suatu perusahaan/ organisasi tentu mempunyai tujuan yang berbeda-beda, dan hal itu biasanya berhubungan dengan manfaat yang diperoleh, seperti:

- Dimungkinkannya akses suatu aplikasi oleh seluruh perangkat yang terkoneksi dalam jaringan [6], sehingga perangkat dapat dimanfaatkan lebih optimal, selain dapat mengurangi biaya untuk pembelian perangkat baru [4] [11].

- Peningkatan keamanan serta kemudahan pengelolaan lingkungan melalui isolasi beban perkerjaan atau aplikasi [6] [13].

- Peningkatan kapasitas aplikasi, dengan mengijinkan user mengakses aplikasi secara bersamaan melalui perangkat yang berbeda [6] [11]

- Pengurangan waktu untuk mengoperasikan aplikasi, melalui pemisahan data ataupun aplikasi tersebut serta penyebaran pekerjaan pada beberapa sistem,

- Optimalisasi pemanfaatan mono sistem,

- Peningkatan reliabilitas serta availabilitas aplikasi atau beban kerja melalui proses pengulangan [6] [11].

Peningkatan Uptime serta percepatan Failure Recovery, juga dapat diberikan oleh virtualisasi disamping beberapa penyederhanaan, seperti: penyederhanaan sistem administrasi, peningkatan kapasitas, dukungan software asli, pengembangan sistem-level, instalasi dan sistem deployment serta ujicoba aplikasi.

Fleksibilitas mesin virtual juga mempermudah proses perpindahan server bila terjadi kesalahan hardware, selain kemampuannya meningkatkan kapasitas hardware, seperti peningkatan kehandalan CPU melalui penambahan inti (core), peningkatan kapasitas memori, kartu jaringan (network card) dan lain-lain [4].

\section{E. Layanan Pengadaan Secara Elektronik / LPSE}

LPSE merupakan unit kerja pada instansi pemerintah yang berfungsi memfasilitasi pe-nyelenggaraan e-proc [14], melalui pengelolaan Sistem Pengadaan Secara Elektronik/SPSE [1]. Eksistensi SPSE mutlak diperlukan selama pelaksanaan proses e-proc sehingga menjaga ketersediaan layanan serta kehandalannya menjadi salah satu tugas pokok yang wajib dikerjakan oleh pengelola LPSE.
Pemilihan serta implementasi teknologi yang sesuai, khususnya dalam pengelolaan server yang dimiliki, diyakini akan sangat mempengaruhi keberhasilan pelaksanaan tugas dan fungsi utama LPSE dan hal itu tentu akan berdampak pula pada peningkatan kinerja LPSE secara keseluruhan.

\section{F. Blue Ocean Strategy (BOS)}

$B O S$ pada prinsipnya merupakan strategi agar dapat keluar dari persaingan melalui penawaran fitur produk atau sistem inovatif, dimana hal tersebut justru terlepas dari perhatian para pesaing [15] dan biasanya memiliki perbedaan mendasar dengan yang selama ini diterapkan dalam organisasi.

Kim dan Mauborgne [16] menjelaskan bahwa BOS bukan sekedar strategi untuk memenangkan suatu persaingan tetapi strategi untuk keluar dari wilayah persaingan dengan menciptakan ruang baru serta membuat para pesaing dan sistem kompetisi menjadi tidak relevan. Inovasi dan kesetaraan nilai menjadi penekanan pada strategi ini [17] dan hal ini terjadi manakala organisasi mengkombinasikan inovasi dengan utilitas/manfaat, harga, serta posisi biaya sebagaimana tersaji dalam Gambar 2.

Inovasi nilai dibangun pada area dimana komponen costs dan value dipengaruhi oleh aksi organisasi secara positif. Langkah penghapusan serta pengurangan konten yang menjadi substansi kompetisi dilakukan sebagai upaya penghematan komponen costs sedangkan peningkatan komponen value dilakukan melalui upaya penambahan serta penciptaan konten yang belum terdapat dipasaran.

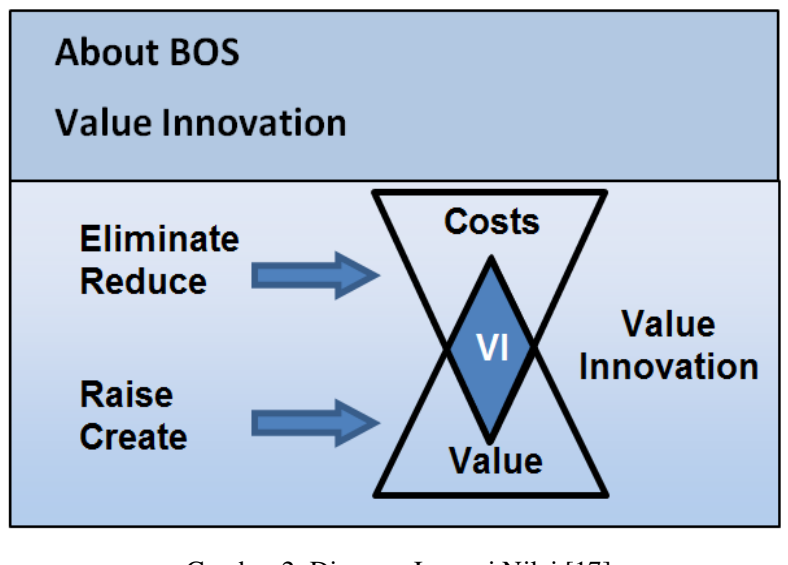

Gambar 2: Diagram Inovasi Nilai [17]

Agar perumusan serta penerapan BOS menjadi sistematis dan praktis, Kim dan Mauborgne [16] mengembangkan 3 hal penting dalam perangkat kerja $B O S$ yaitu:

1. Canvas Strategy yang menjadi kerangka aksi sekaligus diagnosis guna menciptakan $B O S$ yang baik dan bertujuan untuk menangkap posisi organisasi dalam pasar serta memahami faktor-faktor yang menjadi persaingan,

2. Four Actions Framework, yang dipakai merekaulang setiap konten pada komponen value dalam membangun kurva nilai/value baru, dan

3. ERRC Grid (skema Hapuskan - Kurangi -Tingkatkan Ciptakan) yang merupakan pelengkap Four Actions 
Framework dan digunakan untuk mendorong organisasi dalam menciptakan kurva nilai baru.

\section{G. Balanced Scorecard (BSC)}

Konsep BSC awalnya dipublikasikan oleh Kaplan [18] dan digunakan dalam pengukuran kegiatan operasional organisasi dalam skala mikro apakah sesuai dengan sasaran makro dalam visi dan strateginya. BSC adalah metode sistem manajemen yang dapat mentranslasikan visi dan strategi organisasi kedalam aksi nyata, dan terbukti dapat membantu organisasi dalam penerapan strategi bisnis dan pelayanan yang meliputi pengukuran serta pengendalian yang secara cepat, tepat dan menyeluruh bisa memberi dasar pemahaman kepada pimpinan tentang kinerja organisasinya dengan melihat dari empat perspektif yaitu Financial, Customer, Internal Bussiness Process serta Learning and Growth (Gambar 3).

Metode $B S C$ bermanfaat sebagai alat yang efektif untuk perencanaan strategis yaitu sebagai penerjemahan dari visi, misi, peran pokok, faktor penentu keberhasilan, tolak ukur, tujuan, dan target kinerja dalam perbaikan yang komprehensip, terukur, koheren dan berimbang. Perencanaan yang baik, dapat meningkatkan efisiensi dan efektifitas dalam proses usaha, dan memberikan nilai tambah berupa tingkat persaingan yang tinggi, meningkat-kan kinerja dan pertumbuhan kompetisi yang berkelanjutan.

\section{Translating Vision and Strategy: Four Perspectives}

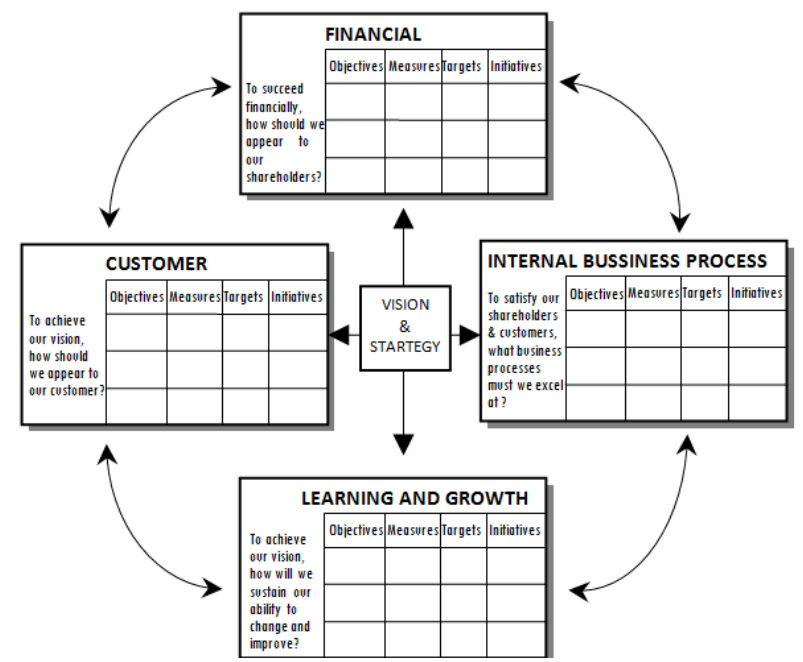

Gambar 3: Perspektif Pengukuran Kinerja Dalam Model BSC [18]

BSC adalah tools yang digunakan untuk memetakan strategi dan menerjemahkannya menjadi rencana aksi. Sebagai salah satu tools manajemen [19], BSC diterapkan juga dalam sistem pemerintahan. BSC organisasi dapat mendefinisikan strategi yang bersifat normatif. Bentuk definitif dari strategi normatif diterjemahkan dalam Key Performance Indicators (KPI). Setiap strategi yang dipetakan menjadi sasaran strategis kedalam perspektif balanced scorecard, harus ditentukan ukuran keberhasilannya.

\section{METODOLOGI}

Penelitian ini menggunakan pendekatan deskriptif kualitatif, mengingat parameter yang diamati merupakan variabel dengan batasan yang tidak jelas secara kuantitatif, namun dapat berpengaruh besar pada pengambilan keputusan maupun penetapan kebijakan yang berkaitan dengan penyelenggaraan layanan.

Data primer diambil melalui kuesioner dengan responden dari pengguna layanan yaitu ULP, PPK, Pejabat Pengadaan serta Penyedia. Tabulasi dan pengolahan data statistik dilakukan dengan software SPSS 20 (uji validitas dan uji reliabilitas), sedangkan analisis menggunakan metode BOS dan $B S C$ dengan pertimbangan bahwa pengelolaan LPSE merupakan suatu kegiatan berbasis TIK yang bersifat dinamis dan umumnya bergerak mengikuti perkembangan TIK, sehingga memberi peluang yang cukup besar bagi terciptanya inovasi nilai dalam penyelenggaraannya. Disamping itu kegitan ini juga melibatkan banyak entitas dengan perspektif yang berbeda, sehingga diperlukan analisis yang lebih mendalam dan menyeluruh pada berbagai perspektif untuk memperoleh hasil yang lebih akurat. Alur proses penelitian disajikan seperti terlihat pada Gambar 4.

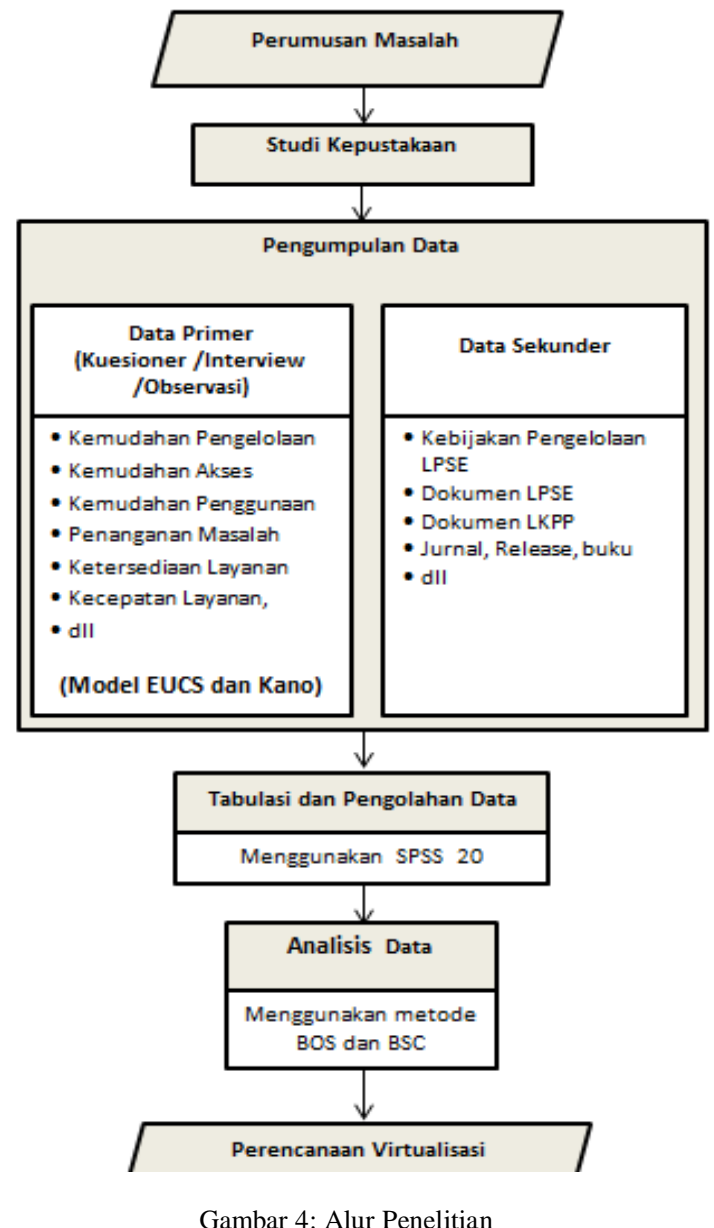

Gambar 4: Alur Penelitian 


\section{HASIL DAN PEMBAHASAN}

\section{A. Perkembangan e-procurement di Kabupaten Badung}

Pelaksanaan e-procurement di Kabupaten Badung dimulai dengan dibentuknya LPSE (2010) dan ULP (2011), dan penerapannya secara penuh dilakukan mulai Tahun Anggaran 2012 dengan perkembangan pelaksanaan seperti tersaji dalam Gambar 5.

Dari Gambar 5 terlihat bahwa jumlah paket pengadaan yang dilaksanakan selama kurun waktu 3 tahun (2012-2014) didominasi oleh pekerjaan konstruksi yang terus meningkat tiap tahunnya, sementara pada 3 jenis pengadaan lainnya jumlah paket lelang bervariasi. Secara umum jumlah total paket pekerjaan yang dilelangkan melalui LPSE tiap tahunnya berkisar antara 400-500 paket.

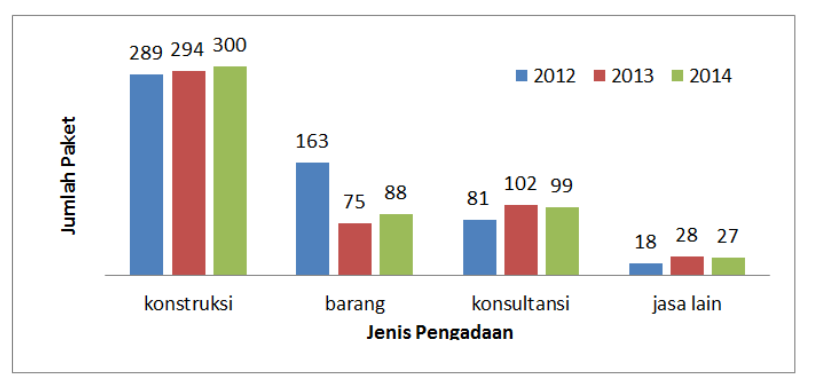

Gambar 5: Perkembangan Jumlah Paket Pengadaan Barang/Jasa Pemerintah melalui e-proc menurut Jenis Pengadaan di Kabupaten Badung Tahun $2012-2014$

Seiring pertumbuhan jumlah paket yang dilelangkan setiap tahunnya, berbagai persoalan terkait, juga semakin mengemuka sehingga LPSE Badung senantiasa berupaya untuk meningkatkan kemampuan serta kinerjanya dan diyakini bahwa peran strategis TIK cukup besar kontribusinya menuju peningkatan kinerja organisasi meskipun tidak selalu bersifat linier [20].

Berbagai inovasi dilakukan seperti Sertifikasi standar mutu pelayanan (ISO 9001:2008) untuk peningkatan mutu penyelenggaraan layanan, implementasi aplikasi Visitor Management System (Sistem Manajemen Pengunjung) untuk memudahkan pengelolaan dan pemantauan penggunaan fasilitas LPSE serta implementasi Teknologi Virtualisasi dalam pengelolaan server LPSE dalam rangka peningkatan ketersediaan dan kehandalan layanan.

\section{B. Uji Statistik}

Hasil uji statistik yang dilakukan terhadap 4 variabel yang diamati menunjukkan bahwa seluruh item dalam instrumen penelitian pada variabel Ketersediaan Layanan (A), Kualitas Layanan (Q) serta Keamanan layanan (S) menghasilkan nilai yang valid dan reliabel, sementara pada variabel Kehandalan Layanan (R) hanya satu item yang menunjukkan nilai tidak valid yang disebabkan oleh inkonsistensi responden dalam menjawab kuesioner yang diberikan sehingga item tersebut tidak disertakan sebagai instrumen penelitian.
Perbandingan nilai persepsi pengguna LPSE terhadap keempat variabel yang diuji berdasarkan hasil Uji Validitas dan Uji Reliabilitas disajikan dalam Gambar 6 dan Gambar 7.

\section{Analisis Blue Ocean Strategy (BOS)}

Bertolak dari pemahaman bahwa prinsip dasar BOS yaitu bagaimana perusahaan / organisasi keluar dari persaingan melalui penawaran fitur produk atau sistem inovatif dengan perbedaan mendasar terhadap produk/ sistem yang selama ini diterapkan dalam organisasi [15] [17], maka perencanaan virtualisasi dan inovasi lain yang telah dilakukan oleh LPSE Badung dapat disebut sebagai upaya implementasi BOS mengingat LPSE Badung merupakan LPSE yang pertama di Indonesia yang menerapkan hal tersebut. Dengan mengacu pada kerangka kerja $B O S$ sebagaimana dikemukakan Kim and Mouborgne yang dikutip Umar, D. and Moengin [17] maka dapat diilustrasikan hubungan antar variabel yang diamati dalam penelitian ini seperti terlihat pada Gambar 8.

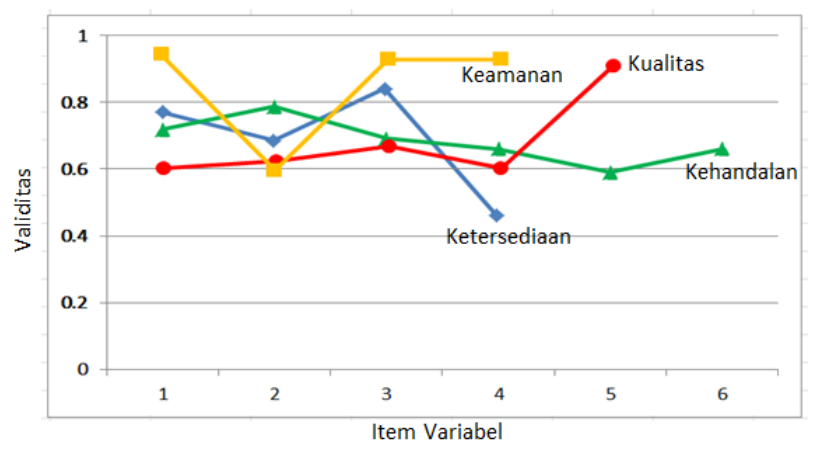

Gambar 6: Perbandingan Nilai Persepsi Pengguna terhadap Variabel yang Diuji Berdasarkan Hasil Uji Validitas

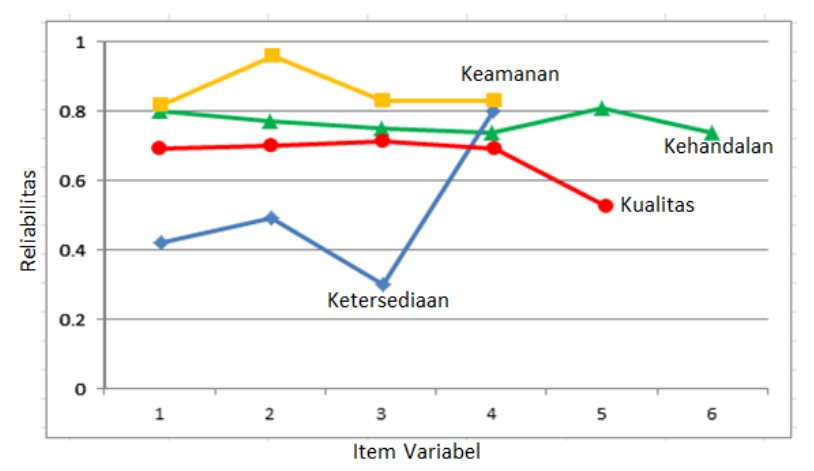

Gambar 7: Perbandingan Nilai Persepsi Pengguna terhadap Variabel yang Diuji Berdasarkan Hasil Uji Reliabilitas

Gambar 8 memperlihatkan bahwa tingkat korelasi variabel Ketersediaan Layanan terhadap Kualitas Layanan (A-Q), Ketersediaan Layanan terhadap Keamanan Layanan (A-S) dan Kualitas Layanan terhadap Keamanan Layanan (Q-S) adalah positif (saling mendukung), sedangkan 3 hubungan lainnya yaitu Ketersediaan terhadap Kehandalan (A-R), Kehandalan terhadap Kualitas (R-Q), serta Kehandalan terhadap Keamanan (R-S) memperlihatkan pola hubungan yang negatif (tidak saling mendukung). Dari pola hubungan tersebut dapat dikatakan bahwa Ketersediaan Layanan berpengaruh terhadap 
Kualitas maupun Kemanan Layanan, sementara Ketersediaan Layanan tidak berpengaruh langsung pada Kehandalan Layanan, artinya ketersediaan layanan tidak serta merta menjamin kehandalannya.

Pengamatan terhadap ekspektasi pengguna terkait kepuasan atas pelayanan LPSE yang direkam berdasarkan tingkat kepentingan serta capaian kinerja dengan beberapa parameter seperti kehandalan infrastruktur, kecepatan proses, kejelasan informasi, kualitas pelayanan secara keseluruhan serta variabel penanganan keluhan dengan parameter kemudahan penyampaian keluhan, respon terhadap penanganan keluhan, penyelesaian terhadap keluhan yang disampaikan dan kepuasan pengguna terhadap penanganan keluhan menunjukkan bahwa penyelenggaraan layanan LPSE Badung telah berjalan dengan baik, ditandai dengan nilai capaian kinerja yang diperoleh mendekati nilai ekspektasi, bahkan pada variabel terkait penanganan keluhan, nilai capaian kinerja melebihi nilai ekspektasi pengguna (Gambar 9).

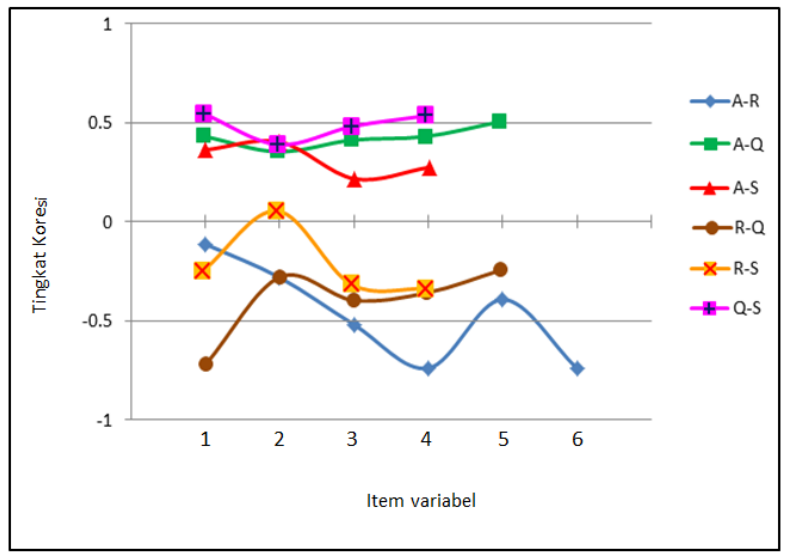

Gambar 8: Perbandingan Tingkat Hubungan/Korelasi antar Variabel pada Persepsi Pengguna terhadap Layanan LPSE Kabupaten Badung

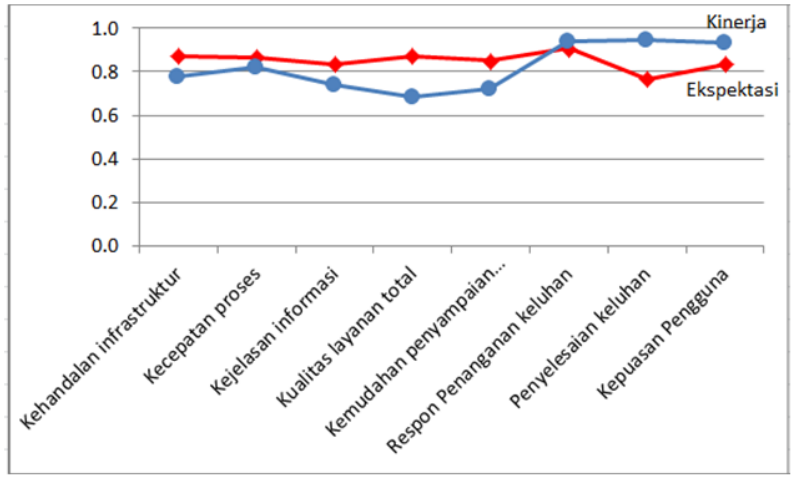

Gambar 9: Perbandingan Nilai Ekspektasi Pengguna dengan Capaian Kinerja Pengelolaan LPSE Kabupaten Badung Tahun 2014

Berdasarkan hasil pengamatan tersebut, maka untuk lebih meningkatkan kinerja LPSE, beberapa instrumen dalam penelitian ini perlu dikelola lebih intensif sebagaimana kerangka kerja 4 langkah pada metode $B O S$ sebagai berikut:

a. Hapuskan (Eleminate)
Kegagalan akses yang berpotensi mengakibatkan kegagalan penyelenggaraan LPSE, mengingat layanan LPSE sepenuhnya berbasis website.

b. Kurangi (Reduce)

Beberapa item yang eksistensinya perlu dikurangi dalam pelaksanaan layanan oleh LPSE adalah:

- Kesalahan/gangguan yang mungkin terjadi dalam operasional LPSE,

- Kesulitan mengakses website LPSE,

- Kesulitan mengoperasikan aplikasi pada website LPSE.

- Gangguan koneksi ke server LPSE

c. Tingkatkan (Raise)

Hal-hal yang perlu ditingkatkan eksistensinya agar penyelenggaraan LPSE lebih baik adalah:

- Ketersediaan informasi yang dibutuhkan

- Kecepatan proses download dan upload dokumen dalam aplikasi

- Kelancaran proses transaksi dalam aplikasi SPSE

- Kemudahan dalam penyampaian keluhan

- Kualitas layanan yang diberikan (Helpdesk)

- Sistem Keamanan yang diimplementasikan

d. Ciptakan (Create)

Ketahanan layanan terhadap gangguan baik gangguan akses maupun gangguan keamanan terhadap data adalah hal yang perlu diciptakan dalam rangka menjamin keberlangsungan penyelenggaraan Layanan LPSE dapat terlaksana dengan baik.

\section{Perencanaan Virtualisasi}

Implementasi Teknologi Virtualisasi nampaknya memang dapat menjadi solusi alternatif yang tepat, mengingat fitur serta kemampuan yang dimiliki dapat bersinergi dengan kerangka kerja empat langkah BOS. Teknologi Virtualisasi dapat menjawab tantangan eliminasi kegagalan akses menuju website LPSE melalui fitur Cluster High Availability serta fitur Fault Tolerant yang dimilikinya, dimana melalui fitur tersebut dimungkinkan sebuah service pada sebuah server dapat berpindah secara otomatis kepada server lainnya hanya dalam waktu singkat tanpa menimbulkan gangguan layanan yang nyata dari sisi pengguna.

Fitur Live Migration pada teknologi ini juga menjadikannya sebagai teknologi yang dapat meningkatkan kehandalan pengelolaan layanan, dimana dengan fitur ini dimungkinkan untuk melakukan maintenance sumber daya TIK yang digunakan tanpa harus mematikan layanan yang sedang berlangsung, sehingga gangguan akses dapat diminimalisir. Penurunan kinerja server dapat dicegah dengan adanya kemampuan pengelolaan sumber daya, dimana manajemen server dalam teknologi ini dapat membagi beban secara berimbang dari sumber daya satu ke sumber daya lainnya, sehingga kelancaran proses transaksi dapat tetap dipertahankan.

Kombinasi pemanfaatan fitur serta kelebihan pada teknologi Virtualisasi pada akhirnya akan menciptakan suatu 
ketahanan layanan dimana ketersediaan layanan dan kehandalan sistem senantiasa dapat terjaga secara baik.

\section{E. Analisis Balanced Scorecard (BSC)}

$B S C$ pada dasarnya merupakan sebuah tools yang digunakan dalam memetakan dan menerjemahkan suatu strategi menjadi rencana aksi [19] [21] [22], yang dapat diaplikasikan juga dalam sistem pemerintahan. Perancangan $B S C$ pada dasarnya adalah menerjemahkan perspektif perngukuran kinerja dalam rangka pencapaian visi dan strategi organisasi kedalam 4 perspektif yaitu Financial, Customer, Internal Bussiness Process, dan Learning andGrowth [18], sementara Sofian [23] mengemukakan contoh perancangan $B S C$ di Institusi Pemerintah dengan pengembangan pada perspektif Customer dari Kaplan [18] menjadi perspektif Stakeholder yang meliputi perspektif Citizens (Customer), Community Caring Capacity dan Building Capacity.

Sebelum penentuan $K P I$, terlebih dahulu perlu penetapan dan pemahaman terhadap visi, misi, tujuan, serta strategi penyelenggaraan layanan dimaksud dan dalam kaitan ini Visi yang ingin dicapai adalah terwujudnya sistem pengadaan barang/jasa pemerintah berbasis TIK yang modern, profesional dan terpercaya, dan untuk me-realisasikannya ditetapkan misi yaitu :

- Peningkatan pemanfaatan TIK dibidang pengadaan barang/jasa pemerintah sesuai kebutuhan dan perkembangan kondisi.

- Peningkatan eksistensi (kualitas, kuantitas serta kapasitas/kemampuan) infrastruktur serta sarana dan prasarana penunjang lainnya di bidang pengadaan barang/jasa pemerintah.

- Peningkatan kompetensi SDM bidang pengadaan barang/jasa pemerintah sehingga dapat bekerja secara lebih profesional.

- Peningkatan kinerja sistem pengadaan barang/jasa secara keseluruhan agar dapat menghasilkan data / informasi yang terpercaya (valid dan up to date), melalui kegiatan pemantauan, koordinasi, kajian serta evaluasi.

Sedangkan tujuan penyelenggaraannya adalah terwujudnya LPSE yang handal, efektif, efisien, transparan dan akuntabel serta meningkatkan partisipatori pengguna layanan, melalui penerapan strategi perencanaan virtualisasi menggunakan metode $B O S$ dan $B S C$. Secara ringkas penetapan $K P I$ pada setiap perspektif $B S C$ dari Perencanaan Virtualisasi LPSE Kabupaten Badung dapat diilustrasikan seperti Gambar 10.

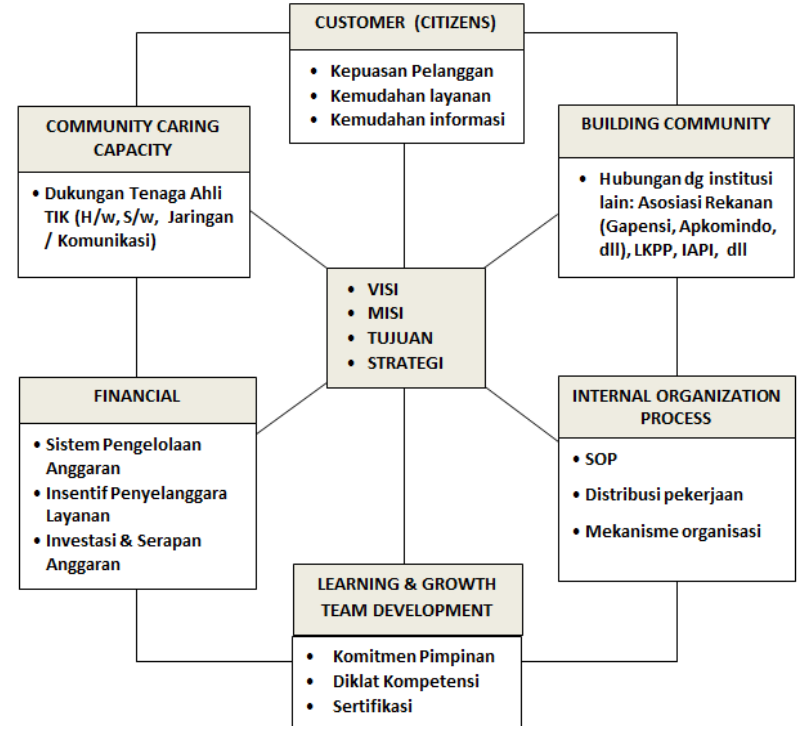

Gambar 10: Perspektif Balanced Scorecard Perencanaan Virtualisasi pada LPSE Kabupaten Badung [23]

\section{KESIMPULAN DAN SARAN}

\section{A. Kesimpulan}

Dari hasil pengamatan dan analisis dalam penelitian ini, dapat disimpulkan beberapa hal sebagai berikut:

a. Perencanaan virtualiasi merupakan solusi yang cukup tepat untuk menjawab tantangan pengelolaan LPSE kedepan dimana eksistensi beberapa fitur penting seperti cluster high availability dan fault tolerance didalamnya dapat memberikan kemudahan pengelolaan sehingga layanan dapat tetap terselenggara secara berkesinambungan.

b. Perencanan virtualisasi dalam kaitan ini menciptakan inovasi nilai bagi LPSE Badung sehingga menjadi langkah nyata menuju Blue Ocean Strategy. Dengan mengacu pada hasil pemetaan instrumen dalam Canvas Strategy, penting diperhatikan serta ditetapkan hal yang mempengaruhi kinerja layanan kedalam kerangka kerja 4 langkah $B O S$ yaitu :

- Meniadakan kegagalan sistem,

- Mengurangi kesalahan aplikasi, kesulitan akses, kesulitan mengoperasikan aplikasi, gangguan koneksi ke server LPSE,

- Meningkatkan ketersediaan informasi yang dibutuhkan, kecepatan proses (download /upload) dokumen, kelancaran proses transaksi (kehandalan sistem), kemudahan dalam penyampaian keluhan, kualitas layanan (helpdesk) yang diberikan, sistem keamanan data, serta

- Menciptakan ketahanan layanan terhadap berbagai gangguan

c. Optimalisai pengukuran kinerja layanan dapat lebih ditingkatkan melalui penetapan Key Performance Indicators /Indikator Kinerja Kunci dari keempat perspektif sebagaimana kerangka kerja analisis $B S C$, dengan terlebih dahulu menetapkan visi, misi, tujuan serta strategi, antara lain : 
- Perspektif Financial: Sistem Pengelolaan Anggaran, Insentif Penyelanggara Layanan serta Investasi dan Serapan Anggaran

- Perspektif Customer: Kepuasan pengguna, kemudahan operasional dan kemudahan memperoleh informasi (perspektif Citizens), dukungan tenaga ahli (perspektif Community Caring Capacity) Sementara pada perspektif Building Community hubungan fungsionalitas dengan komunitas/institusi terkait (Gapensi, Apkomindo, Inkindo, LKPP, IAPI, dll).

- Perspektif Internal Organization Process: SOP, Pendistribusian pekerjaan serta Pola kerja antar unit dalam organisasi.

- Perspektif Learning and Growth Team Development: Komitmen pengambil kebijakan untuk meningkatkan kemampuan serta kompetensi setiap anggota organisasi (LPSE) melalui pelaksanaan pendidikan dan latihan (diklat) dan sertifikasi yang berkaitan (ISO 9001, ISO 27001, dll).

\section{B. Saran}

Dalam penyelenggaraan LPSE, beberapa aspek diyakini sangat berpengaruh terhadap keberhasilan pelaksanaanya, seperti: aspek hukum/legal, manajemen sumber daya, finasial serta aspek teknis terutama yang menyangkut pemilihan teknologi, teknik pengelolaan serta pengelolaan sumber daya yang disesuaikan dengan kebutuhan serta tujuan penyelenggaraan layanan. Dalam penelitian ini tidak dilaksanakan kajian terkait aspek teknis yang diterapkan sehingga hal ini dapat menjadi sebuah saran yang sangat baik untuk dilaksanakan guna melengkapi serta menyempurnakan hasil kajian ini.

Bagi pengelola LPSE disarankan untuk bisa menemukan strategi yang tepat agar seluruh pihak yang terlibat terutama unsur pimpinan selaku pembuat kebijakan dan pengambil keputusan agar dapat berperan aktif serta memberikan komitmen dan dukungannya sehingga perencanaan ini dapat segera diimplementasikan.

\section{REFERENSI}

[1] "Peraturan Kepala LKPP No. 2 Tahun 2010 Tentang Layanan Pengadaan Secara Elektronik," Agustus 2010

[2] O. Kulkarni, S. Bagul, D. Gawali, P. K. Swamy, "Virtualization Technology : A Leading Edge," International Journal of Computer Application, vol. 2, no. 2, pp. ISSN: 2250 - 1797, Apr. 2012.

[3] A. Arfriandi, "Perancangan, Implementasi, dan Analisis Kinerja Virtualisasi Server Menggunakan Proxmox, VMWare ESX, dan Openstack," Jurnal Teknologi, vol. 5, no. 2, pp. 182 - 191, Des. 2012.

[4] R. Umar, "Review tentang Virtualisasi," Journal Informatika, vol. 7, no. 2, Jul. 2013.

[5] M. Ahmed, "Physical server and Virtual Server : The Performance Trade-Offs," European Scientific Journal, vol. 9, no. 12, ISSN: 1857 7881 (Print) e - ISSN 1857- 7431, Apr. 2013.

[6] N. Limantara, "Konsep Dasar Virtualisasi," Popular Articles, 11 Oktober 2014

[7] R. Scroggins, "Virtualization Technology Literature Review," Global Journal of Computer Science and Technology Interdisciplinary, vol. 13, no. 1,2013

[8] R. Suchithra and N., PhD. Rajkumar, "Efficient Migration -A Leading
Solution for Server Consolidation ," International Journal of Computer Applications (0975 - 8887), vol. 60, no. 18, Dec. 2012.

[9] R. Rasian and P. Mursanto, "Perbandingan Kinerja Pendekatan Virtualisasi," Journal of Information Systems, vol. 5, no. 2, Oct. 2009.

[10] T. I. Bayu, I. R. Widiasari, and D. W. Chandra, "Penerapan Teknologi Virtualisasi Tingkat Sistem Operasi pada Server Linux Ubuntu 8.04 Menggunakan OpenVZ," Jurnal Teknologi Informasi -Aiti, vol. 7, no. 1, pp. 1-100, Feb. 2010.

[11] N. S. Ajith and M. Hemalatha, "Cloud Computing for Academic Environment," International Journal of Information and Communication Technology Research, vol. 2, no. 2, pp. 97 - 101, Feb. 2012.

[12] W. Adhiwibowo, "Kernel-Based Virtual Machine untuk Virtualisasi Database sebagai Solusi Kebutuhan Perangkat Keras Studi Kasus Implementasi Sistem Informasi Klinik Kecantikan," Jurnal Transformatika, vol. 10, no. 2, pp. 90 - 91, Jan. 2013.

[13] I. Ali and N. Meghanathan, "Virtual Machines and NetworksInstallation, Performance, Study Advantages and Virtualizaton Options," International Journal of Network Security \& Its Applications (IJNSA), vol. 3, no. 1, Jan. 2011

[14] "Peraturan Presiden Nomor 70 Tahun 2012," tentang Perubahan Kedua Atas Peraturan Presiden Nomor 54 Tahun 2010 tentang Pengadaan Barang/Jasa Pemerintah, Agustus 2012.

[15] F Afiff. (2013) Blue Ocean Strategy dan Ekonomi Kreatif. [Online]. Available: http://sbm.binus.ac.id/2013/04/06/blue-ocean-strategy-danekonomi-kreatif/

[16] W. C. Kim dan R. Mauborgne, "Blue Ocean Strategy," Harvard Bussiness Review, October 2004.

[17] N. Umar and P. M. Moengin, "Penerapan Blue Ocean Strategy di PT X dalam Menghadapi Persaingan Penjualan Automatic Tank Gauging di Indonesia," Jurnal Teknik Industri, vol. ISSN:1411-6340, Sept. 2013.

[18] R.S. Kaplan, "The Balanced Scorecard," Harvard Bussiness Scholl, 1999

[19] W. Nurjaya, "Model Strategic Planning for Information System Menggunakan Balance Scorecard Pada Universitas Komputer Indonesia Bandung," Majalah Ilmiah UNIKOM, vol. 7, no. 1, 2014.

[20] M. W. R Setiyadi. (2014) Inovasi-Teknologi-Informasi-dan-KinerjaOrganisasi. [Online]. Available: https://www.scribd.com/doc/22684692/Inovasi-Teknologi-Informasidan-Kinerja-Organisasi

[21] Putra. (2013) Balanced Scorecard Sebagai Tolok Ukur Penilaian Kinerja Pada Instansi Pemerintah.

[22] B. Nugroho, "Perencanaan Strategis Berbasis Kerangka Kerja Balanced Scorecard (BSC) pada Lembaga Pemerintahan Non Departemen (LPND)," PUSAT DOKUMENTASI DAN INFORMASI ILMIAH , 2013.

[23] Jonathan Sofian. (2008) Perancangan Balanced Scorecard di Institusi Pemerintah. [Online]. Available: https://jsofian.wordpress.com/2008/04/25/ngajar-di-maksitrisakti/\#more-539 